\title{
How The Monosemic Graphics Go Polysemic
}

This paper is a reflection on the semiological tradition after Saussure. The focus here is cartographic. In 1967 Jacques Bertin presented the semiology of graphics, which has had an extensive influence on cartography. Bertin claimed graphics (diagrams, networks and maps) to be a monosemic sign system because graphics transcribe relationships that are previously defined in a data table. This premise is critically revisited regarding maps, resulting in the conclusion that diagrams and networks might be monosemic representations while statistical maps cannot. Polysemy is introduced in statistical mapping because the plan possesses influencing properties on the transcribed meaning, which are not a priori defined in the data table.

$\mathrm{T}$ here are two dominant semiological traditions, one European, influenced by Ferdinand de Saussure (1857 - 1913), called semiology and one North American influenced by C.S. Peirce (1839 - 1914), called semiotics. Semiology and semiotics are notions generally used by French and Anglo-American writers respectively, but they refer to the same discipline: the general study of signs. "The Peircean tradition has provided the most elaborate analysis of the typology of signs and how they "stand-for" their referents, while the Saussurean tradition has had a decisive influence on the semiotic theory of codes (i.e. the study of sign systems)' (MacEachren, 1995, 217-218).

The two traditions differ in their general model of sign referred to as dyadic and triadic models, alluding to the number of elements identified in their sign relationships. In Saussure's dyadic sign model the sign is the union of the two sides that constitute it: a concept and a sound-image. Concept is a term leading into the semiotic dimension of semantics. Apparently, the term 'concept' closely corresponds to the more general semiotic terms meaning and content (Nöth, 1990, 61). Sound-image is a term that according to Saussure's definition 'is not the material sound, a purely physical thing, but the psychological imprint of the sound, the impression that it makes in our senses' (Saussure, 1974, 66). Saussure exemplified his sign model, as in figure 1.a, by illustrating the concept by the image of a 'tree' and the sound-image by the Latin word arbor (Saussure, 1974, 67). Later he decided to replace concept and sound-image by signified and signifier respectively, since 'the last two terms have the advantage of indicating the opposition that separated them from each other and from the whole of which they are parts' (Saussure, 1974, 67). Louis Hjelmslev developed the Saussurian dichotomy but used the notions content and expression. The fact that signified and signifier both are mental entities and independent of any external object in Saussure's theory of the sign (Nöth, 1990, 60), is the most apparent difference from Peirce's sign model (figure 1.b). In Peirce's triadic model the referential object is included as a third category. From one of Peirce's more elaborate definitions, the three correlates of the sign are called: a representamen, an object and an interpretant (Nöth, 1990,42). The representamen is by other semioticians designated as the sign vehicle, the signifier, or the expression (Nöth, 1990, 42). Peirce's second correlate of the sign, the
Jan Ketil Rod

Department of Geomatics

Norwegian University of

Science and Technology

Hogskoleringen $7 G$

N-7491 Trondheim

jan.rod@geomatikk.ntnu.no

INTRODUCTION

"Semiology and semiotics

are notions generally used by

French and Anglo-American

writers respectively, but they

refer to the same discipline: the

general study of signs." 
a)

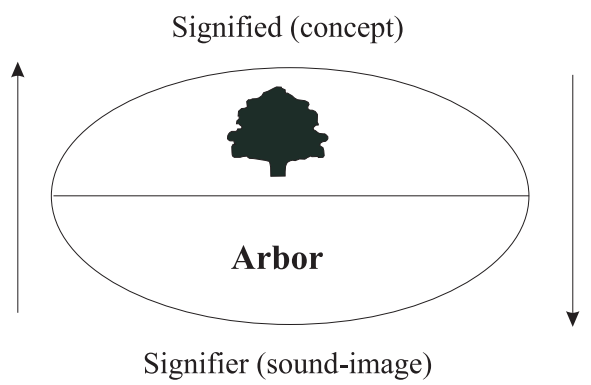

b)

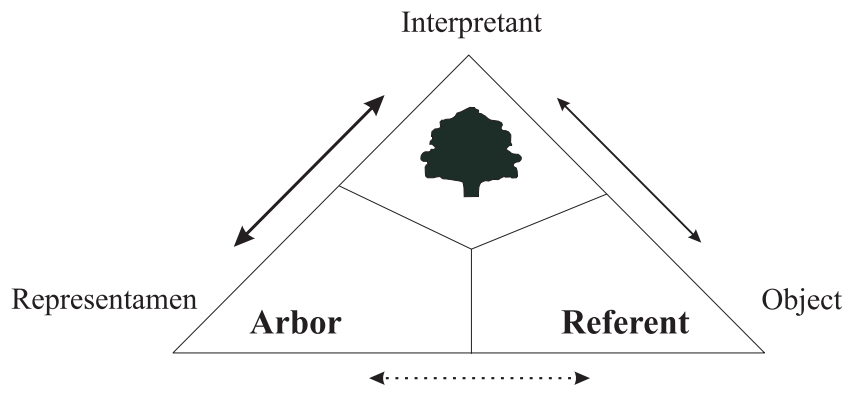

Figure 1. The dyadic sign model (a) adapted from Saussure $(1974,67)$ and the triadic sign model (b) after Peirce. Peirce did not himself make any graphic illustration on his sign model - this one is adapted from Eco $(1976,59)$.

\section{THE GRAPHIC SEMIOLOGY}

"When Bertin defined graphics, he stated that the meanings which we attribute to signs can be monosemic or polysemic." object, corresponds to the referent. This correlate can be a material "object of the world". It can be a "single known existing thing" or a class of things (Nöth, 1990, 42-43). Interpretant is Peirce's term for the meaning of a sign, the signs significance.

Saussure called 'the combination of a concept [signified] and a sound-image [signifier] a sign, but in current usage the term generally designates only a sound-image, a word, for example (arbor, etc.)' (Saussure, 1974, 67 - words in brackets are added). When Bertin defined graphics (1983, 2), he stated that the meanings which we attribute to signs can be monosemic or polysemic. The term sign used by Bertin seems not to correspond with Saussure's 'sign' but with Saussure's 'signifier'. When Bertin uses the term sign, he often does so in the context of polysemy. Similar to how Bertin excludes the notion of code (as will be shown later) he seems to exclude the notion of sign, probably because he coins both terms as associated with polysemic sign systems. 'Mathematics and graphics exclude polysemic signs, by only considering relationships among previously defined elements' (Bertin, 1981, 179). In order to transcribe these relationships, signs were not needed.

The transcription of relationships does not utilize "signs"; it utilizes only the relationship between signs. It utilizes visual variations. Graphics denotes a resemblance between two things by a visual resemblance between two signs, the order of three things by the order of three signs (Bertin, 1981, 177 - originally emphasis).

The relationships to be transcribed are resemblance, order and proportion (Bertin, 1978, 118-119; 1980, 592-593). Without making any reference, Bertin uses the Saussurian terminology and calls the three relationships the three signifieds (Bertin, 1981, 177). Graphics utilizes visual variations between visible marks. This variation has eight variables to its disposal (Bertin, 1983, 7): the dimensions of the plane (variation in $\mathrm{x}$ and $\mathrm{y}$ location), shape, orientation, color, texture, value, and size. Although Bertin does not explicitly indicate that he takes Saussure's ideas as a basis for his own research, this article will interpret Bertin's synthesis along Saussurean lines. I will call the combination of the three relationships as the signifieds (or contents), and the relationships between visual variations as the signifiers (or expressions) of a graphic sign. 
Most cartographers accept the contention that there is a limited set of graphic primitives available for cartographic representation. Some author, however, have found Bertin's graphic semiology incomplete and subsequently extended the visual variable syntactics slightly (Morrison, 1974, 124 and MacEachren, 1994, 33). As Bertin's graphic semiology is closely tied to static classes of representation (point, line, or area), its syntactics is tried extended to also cover $21 / 2$ and 3 dimensional representations (Slocum, 1999, 23). A dynamic variable syntactics is suggested in order to cover dynamic mapping (MacEachren, 1995, 288). This article is an interpretation and modification to Bertin's original ideas and does thus not include an extended syntactics. The problem that polysemy is introduced in mapping should be of relevance for both static and dynamic maps.

As many of his contemporaries and predecessors (i.e. Robinson, 1952), Bertin tried to distance graphics (diagrams, networks, and maps) from art. Several writers have written about the science/art polarity and its relevance for cartography (for instance Krygier, 1995 and Keates, 1996), but little attention is directed towards how the traditional science/art polarity corresponds to monosemic versus polysemic sign systems. 'A system is monosemic when the meaning of each sign is known prior to observation of the collection of signs'. By contrast 'a system is polysemic when the meaning of the individual sign follows and is deduced from consideration of the collection of signs' (Bertin, 1983, 2 - original emphasis). Thus, according to Bertin, graphics are monosemic. Graphics 'is an image that transcribes relations between elements or groups of elements (sets) previously definite' (Bertin, 1978, 121). The elements or sets might be, for instance, two factories.

How do we represent a factory? There is an infinite number of "good" representations. The choice is an art. That is pictography. Factory A employs twice as many workers as factory B. There is only one single representation: show that $\mathrm{A}$ is twice as large as $\mathrm{B}$. This is not an art since there is no choice. This is graphics (Bertin, 1981, 177-178).

Since 'a graphic always begins with a data table' (Bertin, 1978, 121) the relationships between these elements are previously defined, as for instance factory 'A' employs twice as many as factory ' $\mathrm{B}$ ' (figure 2.a). In a monosemic sign system, there is a consistency in meaning like for instance: twice as large: twice as much (see figure 2.b). Size signifies quantity; variation in size signifies variation in quantities.

This constituted, Bertin claimed, a monosemic sign system. To employ a monosemic system means that 'for a certain domain and during a certain time, all the participants come to agree on certain meanings expressed by certain signs, and agree to discuss them no further' (Bertin, 1983, 3 - original emphasis). Following Guiraud $(1975,25)$, the more the relation between the signifier and the signified are precise and widely recognized, the more the sign conforms to a monosemic sign system. Anyone should be able to evaluate the relationships between the marks displayed in figure 3 with a certain degree of accuracy.

A square filled with diagonal lines differs from a square filled with lines having another orientation. We recognize difference in resemblance. A light gray square differs from a dark gray square. We
"Most cartographers accept the contention that there is a

limited set of graphic

primitives available for cartographic representation."

THE MONOSEMIC GRAPHICS

"... the more the relation between the signifier and the signified are precise and widely recognized, the more the sign conforms to a monosemic sign system." a)

Data table

\begin{tabular}{l|l} 
Factory & Employed \\
\hline A & 300 \\
B & 150
\end{tabular}

b)

\section{Graphic}

Figure 2. In a data table (a), the relationships between the elements are previously defined. A graphic (b) is monosemic since it transcribes relations between elements previously defined. 
recognize difference in resemblance and order. A small box differs from a twofold large box. We recognize difference in resemblance, order, and proportion.

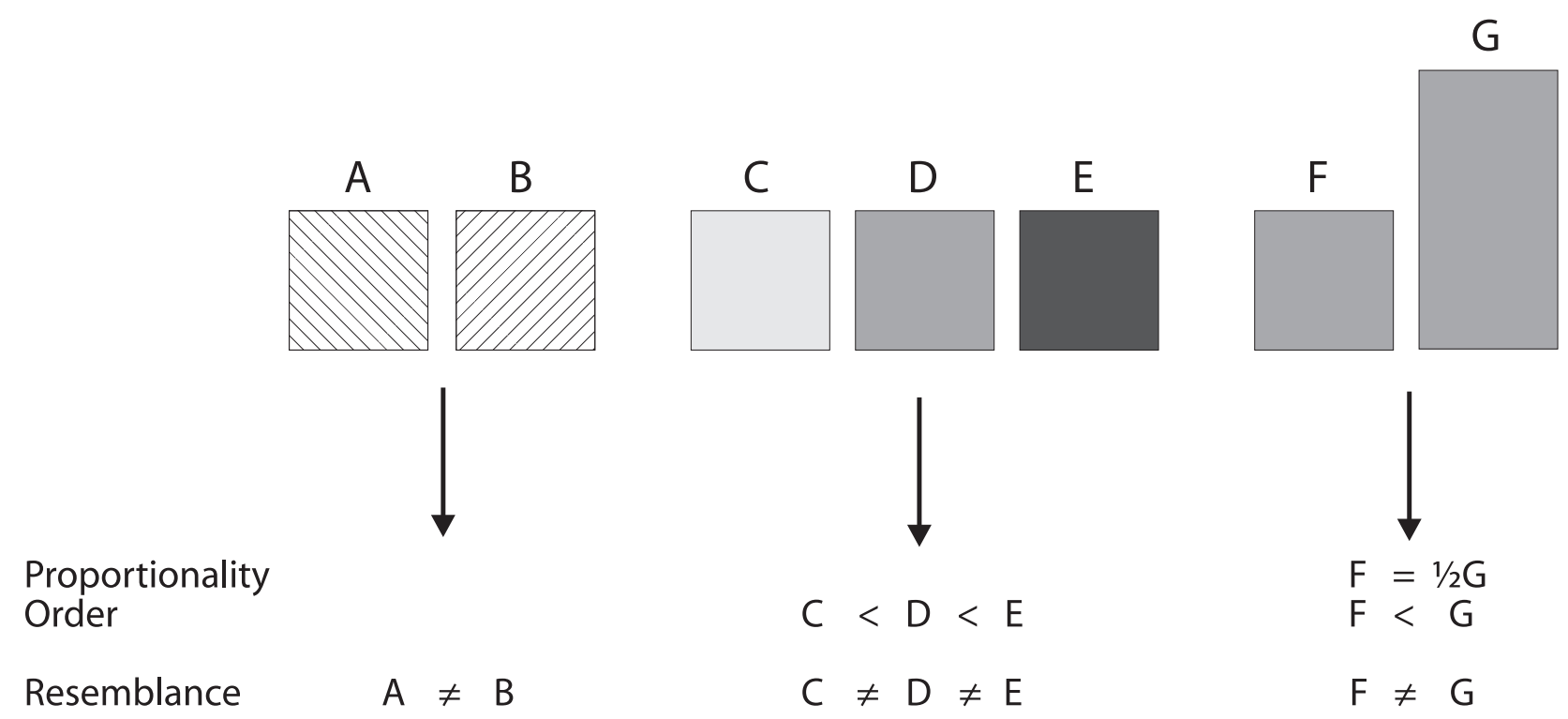

Figure 3. Visual variation between marks and the evaluated relationships.

THE GRAPHIC CODE

"To perceive a polysemic representation requires only one phase of perception: what is it about?"
Bertin emphasizes the way a monosemic versus a polysemic representation is perceived. 'The attention we pay to a diagram or to a map is different from that paid to a painting, a poster or a traffic signal' (Bertin, 1978, 120). To perceive a polysemic representation requires only one phase of perception: what is it about? The aim of a polysemic representation is to define a set or a concept (Bertin, 1981, 176). To perceive a polysemic representation involves the identification of a few concepts from among the unlimited number of imaginable ones. In order to characterize polysemic communication, Bertin $(1978,118)$ used the schema: sender $\leftrightarrow$ code $\leftrightarrow$ receiver (Bertin, 1980, 593), which he had reduced from Shannon and Weaver $(1949,7)$ and Schramm and Roberts $(1971,23)$. This schema in its various forms was popular in numerous studies of maps as the medium for cartographic communication where the encoding of the message (the map making) and its decoding (the map reading) were analyzed. 'The map is the coded "message"' (Robinson and Petchenik, 1976, 27).

'The aim of graphics is to make relationships among previously defined sets appear' (Bertin, 1981, 176 - original emphasis). 'One can than ascertain that any diagram (and consequently any cartography) is or can be considered as the transcription of a data table' (Bertin, 1978, 121). To perceive a graphic requires two distinct phases of perception (Bertin, 1981, 177). 'The first time of perception in 'the graphics' consists in recognizing the three components of this data table' (Bertin, 1978, 121). The three components (Bertin calls them $\mathrm{x}, \mathrm{y}$, and $\mathrm{z}$ ) are the variables (i.e. 'employed'), the units (i.e. factory ' $A$ ' and ' $\mathrm{B}$ '), and the units' values (i.e. ' 300 ' and ' 150 '). In the second phase of perception, the graphic answers questions dealing 'with the relationships existing between the components $\mathrm{x}, \mathrm{y}$ and $\mathrm{z}$ in the data table' (Bertin, 1978, 123), for instance: factory 'A' employs twice as many workers as factory ' $\mathrm{B}$ '. The author and the reader are in exactly the same situation. They are the "actors" who ask the questions in the second phase of perception. According to Bertin, their perception follows the monos- 
emic schema: actor $\leftrightarrow$ three relationships. According to Bertin, the perception of the graphics does not need any code. 'The reader needs no code to "see" order or proportion' (Bertin, 1978, 123).

The term code has two meanings rooted in two quite opposed domains: the secret sphere of cryptography and the public sphere of laws (Nöth, 1990, 206). The introduction of the term in semiotics had a terminological "landslide effect" (Eco, 1984, 166). Only few scholars adhered to the nar-rower definition of code as a correlational device, as mere instructions for the translation of signs from one system of signs to another. Mostly, the term became a synonym of sign system. To which of these definitions Bertin coined the term is difficult to say. Schlichtmann $(1979,81)$ and Board $(1981,61)$ pointed out that Bertin referred to graphic representation as a code in the form of a sign system, but he never explicitly defined the code. Normally, it is within semiotic theory defined as a set of rules for linking expression and contents (Eco, 1976, 36-37), as a correspondence between signifiers and signifieds (Wood and Fels, 1986, 68). Consequently, for semiology of graphics, a code is the set of rules for linking the visual vari-ation and the three relationships. Thus as Board concluded: 'Bertin's rules do form part of what might well be regarded as a code' (Board, 1981, 61).

It follows from the example in figure 3 that different visual variables have different signifying properties. They signify one or more of the relationships of resemblance, order, and proportion. The relationship of resemblance consists of associative and selective properties. A visual variable is associative when it creates an equalized image like in figure 4.a and 4.b. Shape and orientation are associative variables since they do not cause the visibility of the signs to vary.

'Selective perception is utilized in obtaining an answer to the question: "Where is a given category?"' (Bertin, 1983, 67). It seems that orientation (4.b), value (4.c), and size (4.d) are selective while shape (4.a) is not. The use of value and size, however, construct a visual hierarchy favoring the reactor and coal characteristics. Value and size are thus dissociative (not associative) since they cause the visibility of the signs to vary. According to Bertin $(1981,213)$ this hierarchy is an error when unjustified, as, for example, when used to differentiate among characteristics. 'When the characteristics are quantitative, size and/or value are used to represent the quantities (or their order)' (Bertin, 1981, 213 - originally emphasis). Figure 5 summarizes the properties of the visual variables identified by Bertin.

Bertin grouped the visual variables into two main classes, the dimensions of the plane and the a)

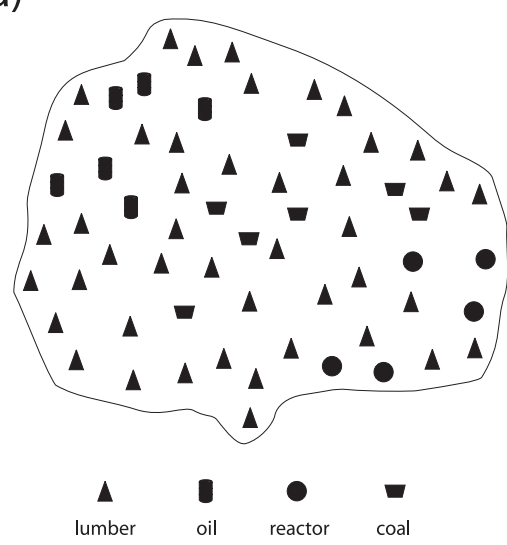

C)

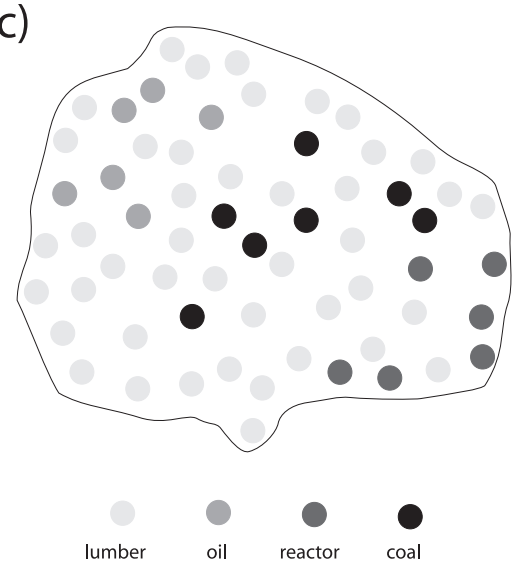

"The term code has two meanings rooted in two quite opposed domains: the secret sphere of cryptography and the public sphere of laws."

\section{SIGNIFYING PROPERTIES}

b)

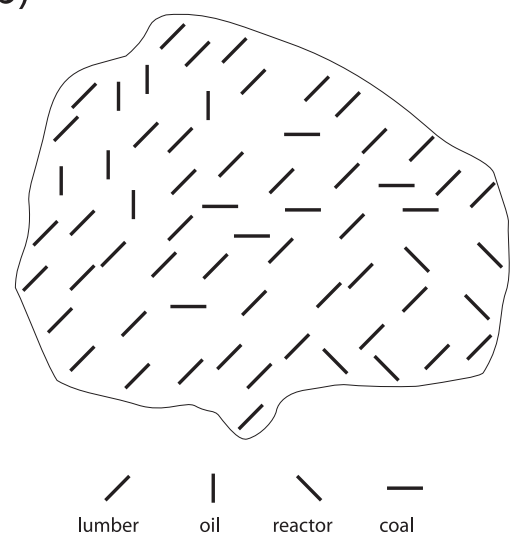

d)

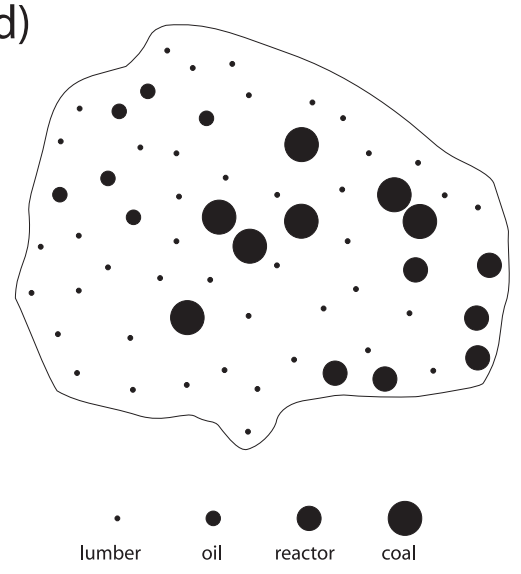

Figure 4. Associative $(a, b)$, selective $(b, c, d)$, and dissociative $(c, d)$ signifying properties. 


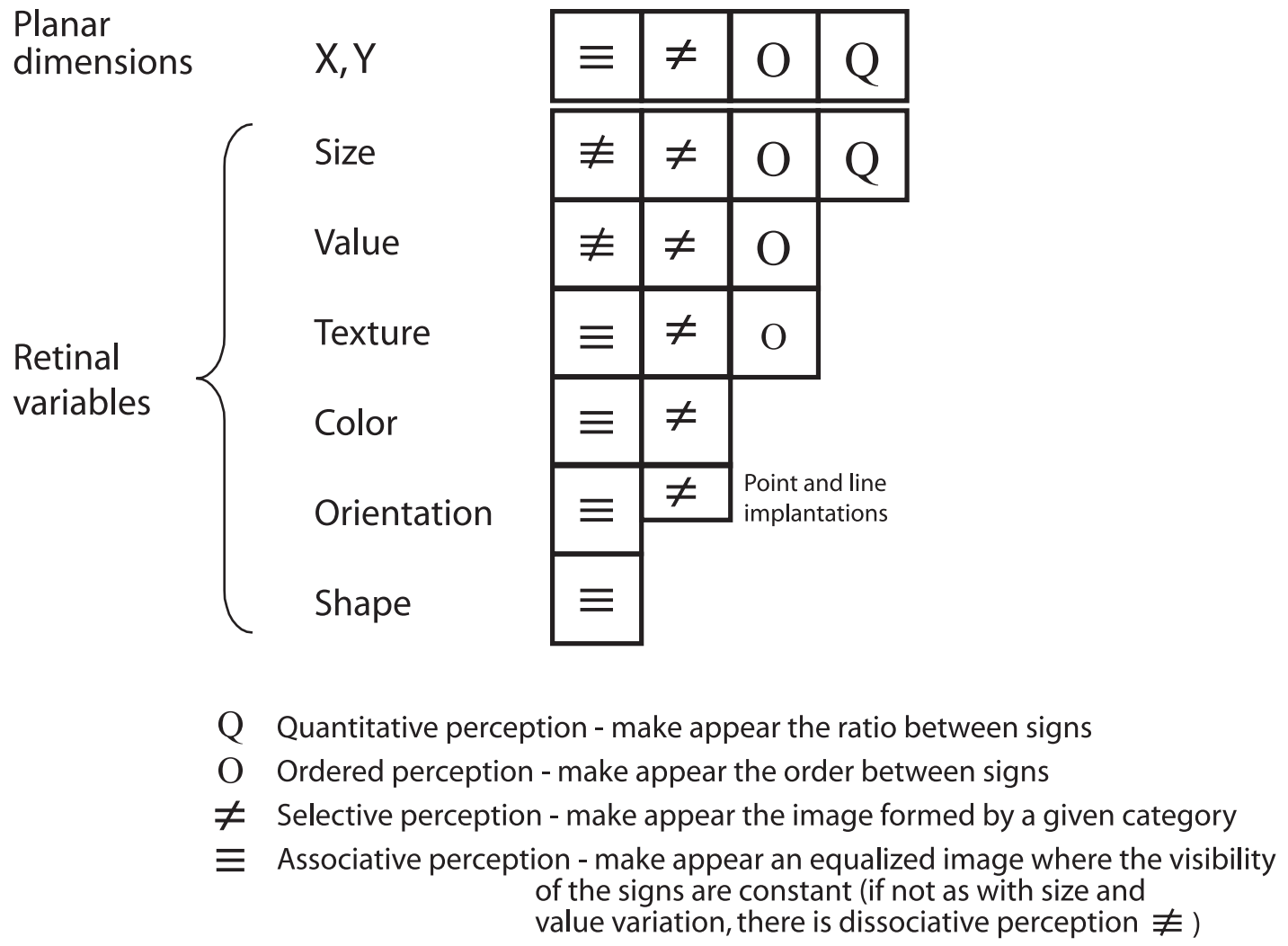

Figure 5. The properties of the visual variables (Adapted from Berlin, 1981, 231).

a)

Perceptual properties of the visual variables

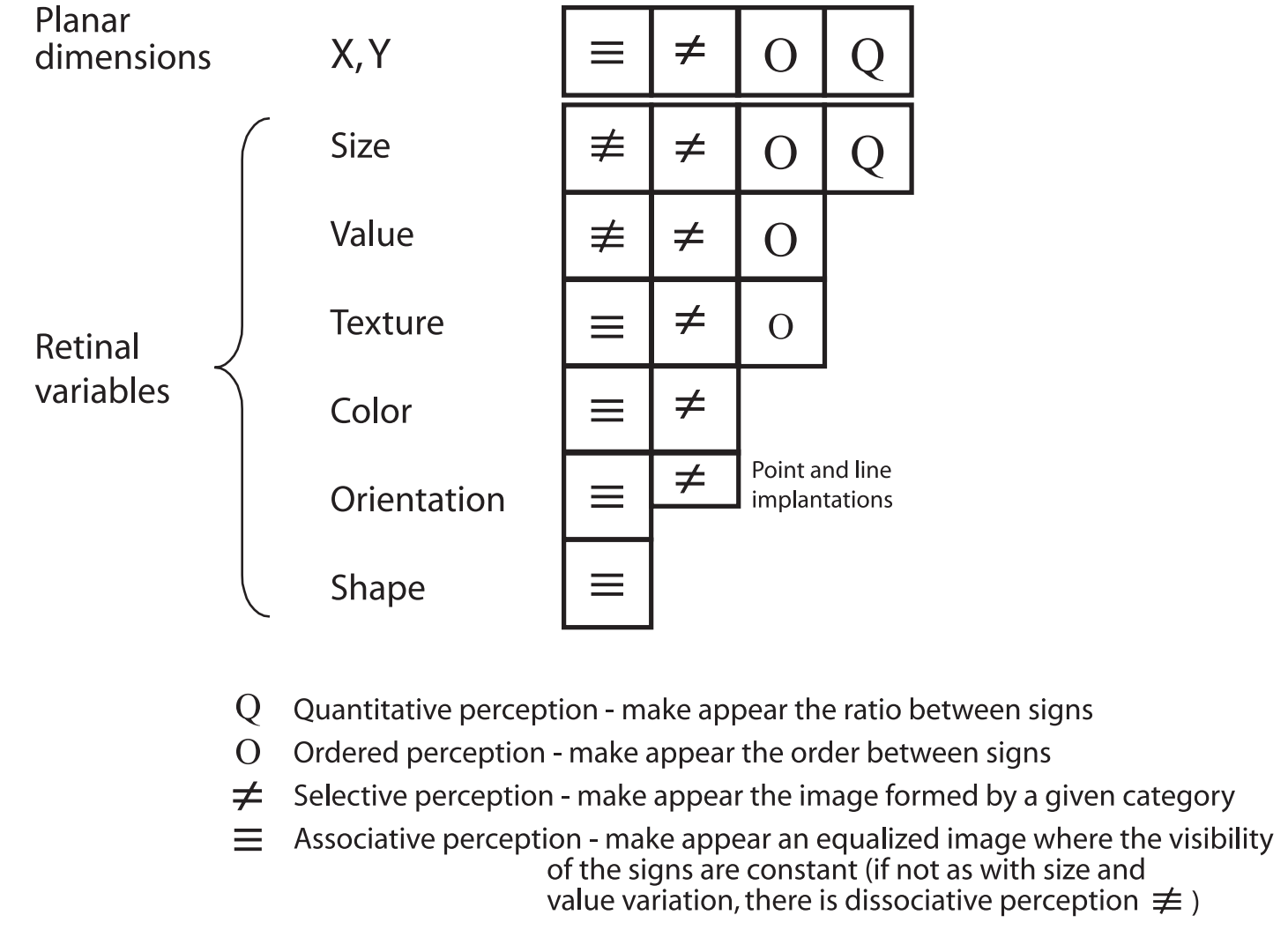

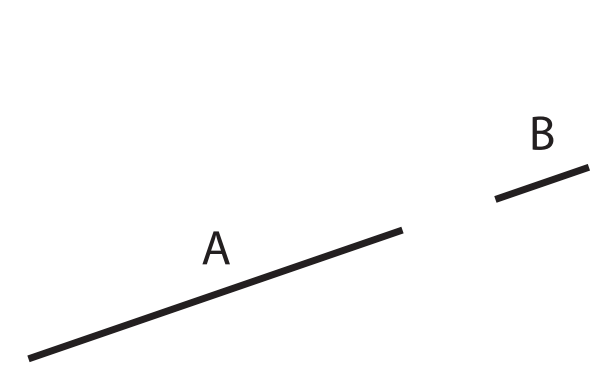

$B$

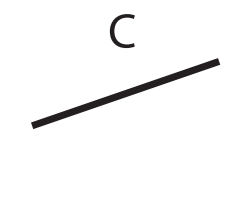

C

b)

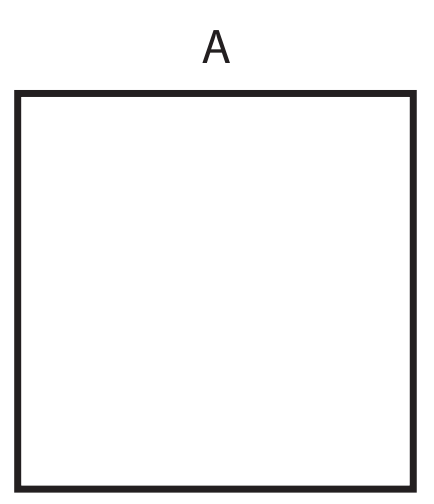

B

Figure 6. Lines and areas as individual localized signs. 
retinal variables. In cartographic theory, the properties of the latter have achieved most attention. The properties of the former have more or less been overlooked, although 'the plane provides the only variables possessing all four perceptual properties' (Bertin, 1983, 49), that is: associative, selective, ordered, and quantitative. In order to "prove" that a variation in position is ordered and that difference in position is quantitative, Bertin used an example with three line segments as in figure 6.a (Bertin, 1983, 49).

Bertin claimed that anyone could evaluate the relationships displayed in figure 6.a with a certain degree of accuracy:

$$
\mathrm{A}>\mathrm{C}>\mathrm{B} \quad \mathrm{A}=2 \mathrm{C} \quad \mathrm{B}=\mathrm{C} / 2
$$

Bertin continued with stating that the plan permits us to add segments (Bertin, 1983, 49). Areas and lines are aggregates of points. Schlichtmann $(1991,265)$ treats space (points or aggregates of points like lines and areas) as individual localized signs, isolated by a notional (content-related) criterion (example: 'country') and a graphic (expression-related) criterion (example: area symbols which indicate a country). Similar to Bertin's example above, anyone should be able to evaluate the relationships displayed in figure 6.b with a certain degree of accuracy:

$$
\mathrm{A}>\mathrm{C}>\mathrm{B} \quad \mathrm{A}=2 \mathrm{C} \quad \mathrm{B}=\mathrm{C} / 2
$$

In this article, I adopt Schlichtmann's term 'locational signs' which I will use for the administrative units used for statistical mapping.

The diagram in figure 7.a shows two components: (1) quantities in thousands of salaried workers, according to (2) five 'départements' in Brittany. When constructing a diagram that depicts numerical information, like the one in figure 7.a, one does not need the retinal variables in order to transcribe quantities since one dimension covers the categories (the $x$-axis) and one dimension covers the quantities (the y-axis). Figure 7.b represent a different situation. 'In cartography, the geographic component occupies the two planar dimensions' (Bertin, 1983, 58). Consequently, 'we must seek new variables to represent additional components. These are the "elevated" or "retinal" variables' (Bertin, 1983, 59).

Figure 7.b is an example of visual variation "above" the plane. The base map composes the two dimensions of the plane. In order to represent a previously defined relationship, it is the variables of the third dimension or the 'retinal' variables that need to be called upon. It is a relationship of proportions; thus, the visual variable size must be used for its representation. The 'retinal' variable size is inscribed "above" the plane and is, according to Bertin, independent from it - independent in the sense that the eye can perceive its variation without requiring movement. Eye movement occurs when the map perceiver needs to scan or read the map in order to conceive the overall meaning (Bertin, 1983, 62-63). Bertin claims that the transcription of meaning (relationship of resemblance, order, or proportions), is left to the 'retinal variables' alone.

To claim that the transcription of meaning is left to the 'retinal variables' alone is a pronouncement I find difficult to accept. I believe that the properties of the plan exert influence on how maps are imbued with meaning. The size of the administrative units to which the marks correspond, make up additionally signs - localized signs. Consequently, in a comparison of two graphic depictions, there are three relations that need to be considered (see figure 8).

First, it is the visual variation "above" the plan, which generate the denotative code (1). Second, 'what people see when confronted with proportional symbols related to areas is a ratio between the size of the symbol and the size of the enumeration area it refers to' (Kraak and Ormeling, 1996, 135). This generates an interlocking code (2). Third, to say that
"... 'the plane provides the only variables possessing all four perceptual properties', that is: associative, selective, ordered, and quantitative."

\author{
SUPERIMPOSING LEVELS OF \\ MEANING
}

"In order to represent a previously defined relationship, it is the variables of the third dimension or the 'retinal' variables that need to be called upon." 
a)

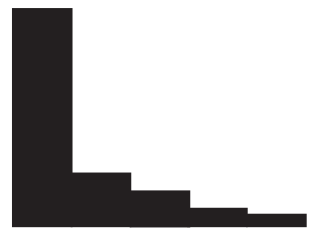

L.A. F. I.V. M. C.N. b)

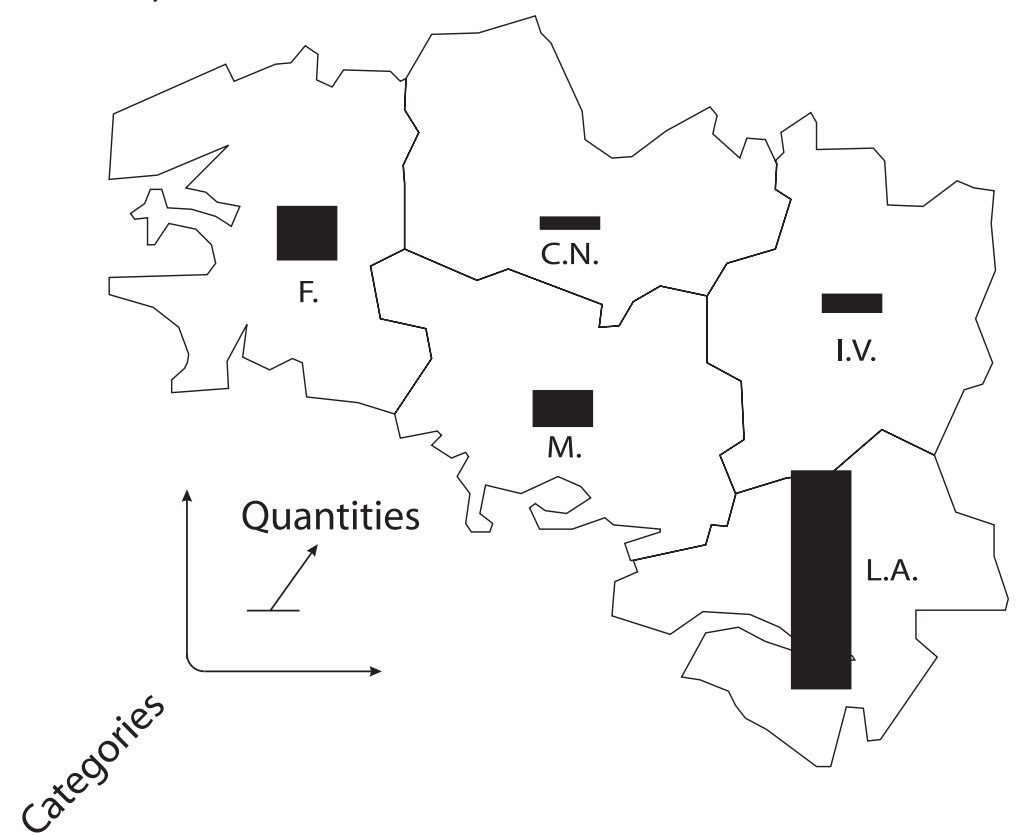

Figure 7. When the various categories are spatially defined and the information produces a map, both dimensions are utilized for their representation. The representation of quantities must be transcribed by "elevated" or "retinal" variables (Bertin, 1983, 58-59).

\section{Mark A}
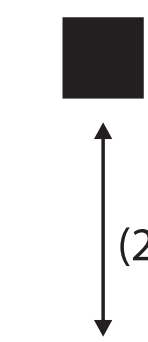

(2)

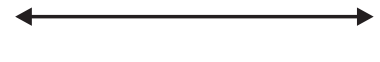

(1)

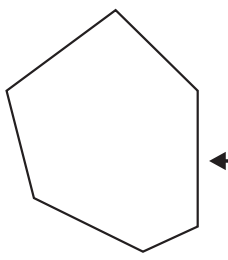

(3)

Area A

'space is utilized to signify space' (Bertin, 1983, 58) is too simple. As the administrative units differ in size, the size variation transcribes additional relationships of resemblance, order, and proportion. This generates a superimposed code (3). In this article, only the denotative and superimposed codes are subject for investigation.

The meaning transcribed by the 'retinal variables' alone, is a denotative semiotic (see figure 9). 'In a denotative semiotic an expression plane denotes a content plane' (Eco, 1994, 182). Eco uses as Saussure a dyadic sign model, but exchanged, like Hjelmslev did, the terms signified and signifier by content and expression respectively. Schlichtmann (1979, $1985,1991)$ adopts the same terminology. The content of map entries, he outlines, have both plan-free and plan components. 'Items of plan information are denoted, i.e. directly expressed, by plan characteristics of symbols' (Schlichtmann, 1985, 24). Plan information is also connoted (Schlichtmann, 1985, 29 - footnote 11). In connotative semiotic 'both expression and content of a denotative semiotic become in turn the expression plane of a new content plane' (Eco, 1994, 182). Connotation is a mediated meaning, i.e., a meaning released by another more basic meaning (Schlichtmann, 1990, note 3, Eco, 1976, 55-56).

Figure 8. Denotative code (1), interlocked code (2), and superimposed code (3). The basic meaning in figure 9.c is that 
a)

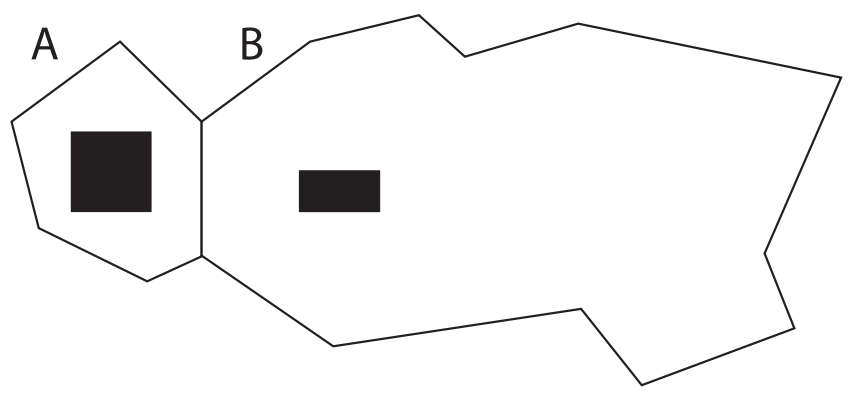

b)

Denotative semiotic

\section{Expression}

\section{Content}

\begin{tabular}{|l|l|ll|}
\hline & & Proportions & $A=2 B$ \\
& & Order & $A>B$ \\
A & $B$ & Resemblance & $A \neq B$ \\
\hline
\end{tabular}

c)

\section{Connotative semiotic}

\begin{tabular}{|c|c|r|}
\hline \multicolumn{2}{|c|}{ Expression } & Content \\
\cline { 1 - 1 } Expression & Content & \\
\hline
\end{tabular}

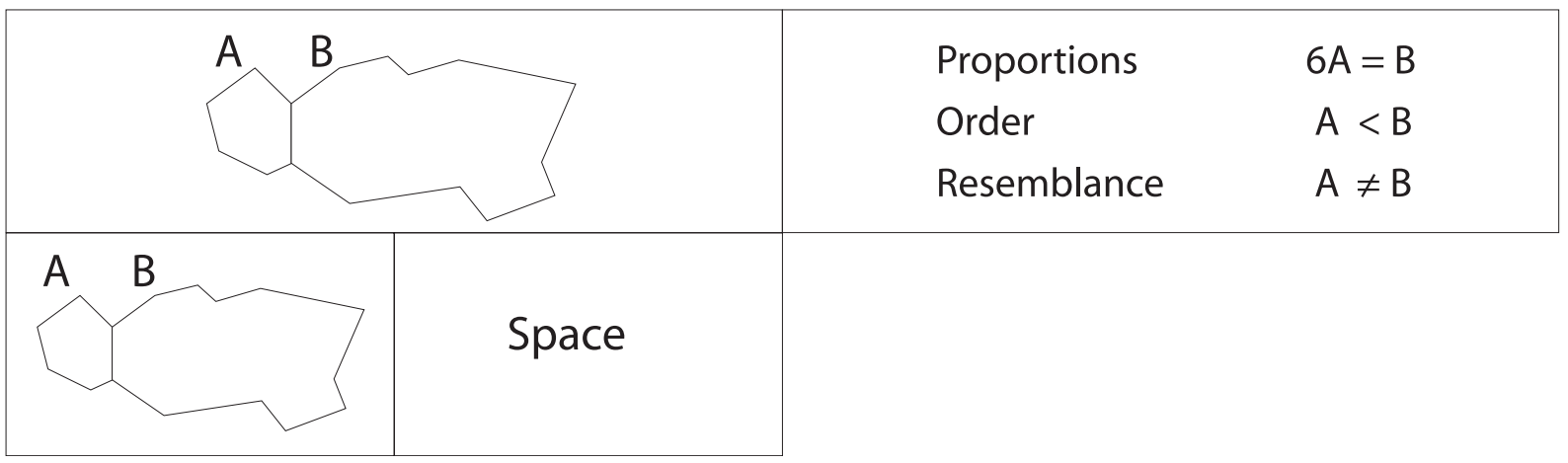

Figure 9. Denotative and connotative semiotic when the administrative units varies in size.

'space is utilized to signify space' (Bertin, 1983, 58). 'Whatever else the map may do, in any case it represent a space, and it represents by means of a space' (Schlichtmann, 1985, 24). As shown in figure 9, areas and thus base map units possess signifying properties, which mediate an additional meaning. Inconsistency might arrive in the transcribed meaning if the denoted meaning, for instance twice as large: twice as much $(\mathrm{A}=2 \mathrm{~B})$ differs from the connoted one $(6 \mathrm{~A}=\mathrm{B})$.

Probably the only situation in mapping where the graphic message would depend on the 'retinal variables' alone is when the size and form of the area patches is equal and aligned regularly like in figure 10. In nearly 
a)

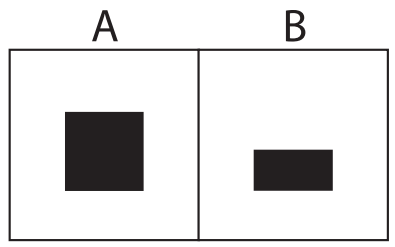

b)

\section{Denotative semiotic}

\begin{tabular}{|c|c|c|}
\hline Expression & \multicolumn{2}{|c|}{ Content } \\
\hline & Proportions & $A=2 B$ \\
\hline & Order & $A>B$ \\
\hline A & Resemblance & $A \neq B$ \\
\hline
\end{tabular}

c)

\section{Connotative semiotic}

\begin{tabular}{|c|c|c|}
\hline \multicolumn{2}{|c|}{ Expression } & Content \\
\hline Expression & Content & \\
\hline
\end{tabular}

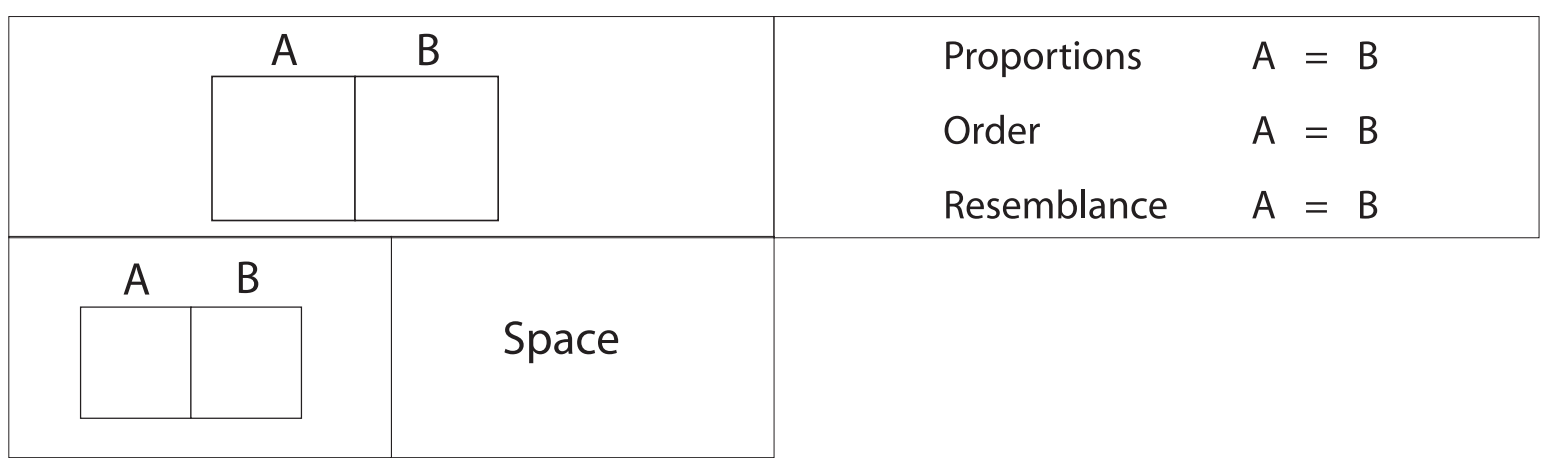

Figure 10. Denotative and connotative semiotic for aligned grid cells.

all situations in statistical mapping, however, administrative units vary in size as in figure 9 (for simplicity ignore that the area patches also differ in shape). If the size and form vary too much between administrative units, a biased picture of the statistical theme might occur. The graphic message does thus not depend on the 'retinal variables' alone. The problem under discussion has been well recognized in empirical research on statistical mapping (Dykes, 1994:105). In this article, the problem has been tackled in a theoretical context. 
an aggregate of superimposed and interlocking codes. This article has tried to show that polysemic meaning emerges also for the particular graphic language: statistical mapping. In statistical mapping, it is shown; one is also dealing with an aggregate of superimposed and interlocking codes in addition to the denotative one. In order to better understand the way a map transcribes meaning, it is necessary to consider the dimension of the plane not independently from the retinal variables, but as an influencing part of the graphic sign system. The administrative units do not only signify space, they additionally portray relationships of resemblance, order and proportion. These relationships are not previously defined in the data table. Consequently, they represent a second connotative meaning. In statistical mapping, therefore, the monosemic graphics go polysemic. Inconsistency might arrive if the connoted meaning does not correspond with the denoted meaning. In order to avoid inconsistency, mapmakers should be using aligned grid cells with equal size and form. The grid cells will then connote equally and consequently not interfere with the denoted meaning. Another solution is to use cartograms. According to Bertin's definition on monosemic representations, cartograms are monosemic since the sizes of the administrative units are scaled according to previously defined relationships in the data table.

I thank Dr. Axel Baudouin, Professor Ferjan Ormeling and three anonymous referees for their critical and constructive comments on earlier versions of this manuscript.

Bertin, J. 1978. Theory of communication and theory of 'the graphic'. International Yearbook of Cartography. 18:118-126.

Bertin, J. 1980. The basic test of the graph: A matrix theory of graph construction and cartography. In Processing of Visible Language 2, eds. P. A. Kolers, M. E. Wrolstad, and H. Bouma. 585-604. New York: Plenum Press.

Bertin, J. 1981. Graphics and Graphic Information Processing. Berlin: Walter de Gruyter. Originally published as La graphique et le traitement graphiques de l'information. (Paris: Flammarion, 1977).

Bertin, J. 1983. Semiology of graphics: Diagrams, networks, maps. Madison: University of Wisconsin Press. Originally published as Sémiologie graphique. Les diagrammes - les réseaux - les cartes. (Paris: Mouton \& Gauthier-Villars, 1967).

Board, C. 1981. Cartographic communication. Cartographica. 18:2:42-78.

Dykes J. 1994. Area-value data: New visual emphases and representations. In Visualisation in geographical information systems, eds. H. M. Hearnshaw and D. J. Unwin, 103 - 114. Chichester: Wiley.

Eco, U. 1976. A Theory of semiotics. Bloomington: Indiana University Press.

Eco, U. 1984. Semiotics and the philosophy of language. Bloomington: Indiana University Press.

Eco, U. 1994. Denotation/connotation. In Encyclopedic dictionary of semiotics. 2nd ed., ed. T. A. Sebeok. Berlin: Mouton de Gruyter, 1:181-183.
ACKNOWLEDGEMENTS

\section{REFERENCES}


Guiraud, P. 1975. Semiology. London: Routledge \& Kegan Paul. Originally published as La sémiologie. (Paris: Presses universitaires de France; 1971).

Keates, J. S. 1996. Understanding maps. 2nd ed. Essex: Longman.

Kraak, M. J. and Ormeling, F. J. 1996. Cartography - Visualization of spatial data. Essex: Longman.

Krygier, J. B. 1995. Cartography as an art and a science? Cartographic Journal. 32:6: 3-10.

MacEachren, A. M. 1994. Some truth with maps: a primer on symbolization \& design. Association of American Geographers. Resource publications in geography.

MacEachren, A. M. 1995. How maps work: Representation, visualization and design. New York: Guilford Press.

Morrison, J. L. 1974. A Theoretical framework for cartographic generalization with emphasis on the process of symbolization. International Yearbook of Cartography. 14: 115-127.

Nöth, W. 1990. Handbook of semiotics. Bloomington: Indiana University Press.

Robinson, A. H. 1952. The Look of Maps - An Examination of Cartographic Design. Madison: The University of Wisconsin Press.

Robinson, A. H. and Petchenik, B. B. 1976. The nature of maps: Essays toward understanding maps and mapping. Chicago: University of Chicago Press.

Saussure, F. 1974. Course in general linguistics. Rev. ed. London: Owen. Originally published as Cours de linguistique générale. (Paris: Payot, 1916).

Schlichtmann, H. 1979. Codes in map communication. The Canadian Cartographer. 16:1: 81-97.

Schlichtmann, H. 1985. Characteristic traits of the semiotic system 'map symbolism'. Cartographic Journal. 22:1: 23-30.

Schlichtmann, H. 1991. Plan information and its retrieval in map interpretation: The view from semiotics. In Cognitive and linguistic aspects of geographic space, eds. D. M. Mark and A. U. Frank. Dordrecht: Kluwer Academic Publishers. 263-284.

Schramm, W. and Roberts, D. F. 1971. The process and effects of mass communication, rev. ed. Urbana: University of Illinois Press.

Shannon, C. E. and Weaver, W. 1949. The mathematical theory of communication. Urbana: University of Illinois Press.

Slocum, T. A. 1999. Thematic cartography and visualization. Upper Saddle River, N.J.: Prentice-Hall.

Wood, D. and Fels, J. 1986. Design on signs / Myth and meaning in maps. Cartographica. 23:3: 54-103. 